\title{
GMR
}

\section{Population genetic structure and its implication in the conservation of Schizopygopsis pylzovi in Yellow River as inferred from mitochondrial DNA sequence analysis}

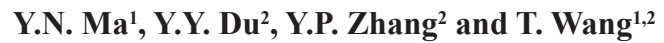 \\ ${ }^{1}$ Department of Chemistry and Life Sciences, \\ Gansu Normal University for Nationalities, Hezuo, Gansu, China \\ ${ }^{2}$ Gansu Key Laboratory of Cold Water Fishes Germplasm Resources and \\ Genetics Breeding, Gansu Fishery Research Institute, Lanzhou, Gansu, China \\ Corresponding author: T. Wang \\ E-mail: aqhongqi@qq.com
}

Genet. Mol. Res. 15 (3): gmr.15038480

Received January 25, 2016

Accepted April 15, 2015

Published August 29, 2016

DOI http://dx.doi.org/10.4238/gmr.15038480

Copyright (C) 2016 The Authors. This is an open-access article distributed under the terms of the Creative Commons Attribution ShareAlike (CC BY-SA) 4.0 License.

\begin{abstract}
To assess the genetic diversity, structure, and population dynamics of Schizopygopsis pylzovi, we examined the changes in mitochondrial DNA sequences (the mtDNA control region and the Cyt $\mathrm{b}$ gene; $1835 \mathrm{bp}$ ) in 304 individuals from nine populations. The samples were segregated into 112 haplotypes, with high haplotype diversity and low nucleotide diversity. The haplotype diversity was highest in the Minhe (HS) range of Huangshui River and lowest in the Weiyuan (WY) range of Weihe River. Analysis of molecular variance showed that $69.64 \%$ of the total genetic variance was contributed by within-the-group variation and $30.36 \%$ was contributed by among-the-group variation. Pairwise $F_{\mathrm{ST}}$ revealed significant divergence between the populations. The $F_{\mathrm{ST}}$
\end{abstract}


between the MT and WY was highest, and that between the YZ and YJ was lowest. The neighbor-joining phylogenetic tree demonstrated that all geographic populations were not monophyletic, but overlapped each other, indicating that the duration of geographical isolation was not long enough or the populations had not yet reached significant genetic isolation or differentiation at the monophyletic level. Tajima's $\mathrm{D}$ and Fu's Fs were negative and statistically significant, indicating that $S$. pylzovi had experienced certain population expansion events, which is consistent with the hypothesis that the headwater area of the Yellow River was dramatically affected by the geological and climatic upheaval during the Quaternary ice age. Our analysis indicated that the management units corresponding to the WY population should be managed and conserved first. In situ conservation is first recommended to protect the original habitat from further destruction.

Key words: Schizopygopsis pylzovi; Mitochondrial DNA; Genetic structure; Genetic diversity; Conservation strategy

\section{INTRODUCTION}

The Yellow River is an important river in China, which flows from west to east. This region is rich in biodiversity due to its unique geographic features. The upper reach of the Yellow River is famous for its distinctive fish fauna. Thirty fish species are reported to reside in this area, many of which are endemic. However, few studies have been conducted to examine the species of fish present in the Yellow River, particularly the endemic ones. Schizopygopsis pylzovi is categorized into the subfamily Schizothoracinae of family Cyprinidae under the order Cypriniformes. It is mainly distributed in upstream regions of the Yellow River and its tributaries (Wu and $\mathrm{Wu}, 1992)$. The species is often found near gravel crevice habitats on the bottom of rivers and gently flowing waters, and feeds on tiny aquatic animals and plants. It has an important position in the food chain for freshwater ecosystems on the Tibetan plateau. S. pylzovi has a short breeding season, slow growth, late maturity, low fecundity, along with other biological characteristics typical of fish. In recent years, owing to human activities and environmental impacts, the habitat of $S$. pylzovi has been deteriorating and shrinking significantly, leading to a drop in its population (Qi et al., 2007). S. pylzovi is one of the key protected species of Gansu and Qinghai Provinces. In this context, evaluation of the germplasm resources of $S$. pylzovi is urgently needed.

Habitat fragmentation changes population genetic structure and dynamics, and is an important cause of population degradation and loss of genetic diversity. The level of genetic diversity and population genetic structure is a result of the combined action of various factors, such as evolutionary history of species, its distribution pattern, and ways of its migration and breeding. Studies on the genetic diversity of species can help in understanding its population genetic structure and dynamics, and could, therefore, contribute in formulation of reasonable protection strategies (Avise, 2000). Understanding of the prevailing spatial distribution and genetic diversity of population, as well as the determination and conservation of the evolutionarily significant unit, is expected to be crucial for effective protection and management of S. pylzovi.

Genetics and Molecular Research 15 (3): gmr.15038480 
Molecular markers have been used in the assessment of genetic diversity and population genetic structure of species (Craft et al., 2010; Simplicio et al., 2015). The population structure and genetic diversity of Zelkova schneideriana from seven populations were analyzed using two chloroplast regions; the results suggested that $Z$. schneideriana should be protected by an in situ conservation strategy (Liu et al., 2016). Genetic diversity of Lepturichthys fimbriata collected from three sites in the Yangtze River was determined by analyzing genetic data from 14 polymorphic microsatellite loci. A high genetic diversity was observed in this analysis, but significant differences were observed among the three populations (Zhang et al., 2012). The genetic structure and integrity of the native, critically endangered Singidia tilapia was analyzed based on the mitochondrial DNA (mtDNA) control region and eight nuclear microsatellite loci (Paul et al., 2011). In this study, no mtDNA introgression was detected between the native and invasive species from Lakes Kanyaboli and Namboyo; however, low levels of nuclear admixture was observed primarily in species from Oreochromis niloticus to O. esculentus.

mtDNA, which is a maternally inherited genetic material, has higher mutation rates. Mutations that are fixed, forming the polymorphic loci, can reflect the population genetic structure and are ideal as molecular markers for studies on population genetics and phylogeny (Billingtong and Hebert, 1991; Wu et al., 2010; Cheng et al., 2015). Zhao et al. (2006) observed no significant differences in cytochrome $b$ gene $(c y t b)$ in 16 individuals of two Schizopygopsis species from the Yellow River and Chaidamu Basin. The genetic differentiation was, however, observed using the mtDNA control region in 99 individuals of $S$. pylzovi collected from four locations (Qi et al., 2007). Other researches have, to date, mainly concentrated on shape characteristics, classification, ecological environment, and mitochondrial genome, etc. of $S$. pylzovi (Wu, 1964, 1984; He and Chen, 2007; Duan et al., 2009). However, very little research has been conducted on the distribution patterns of genetic diversity and differentiation of $S$. pylzovi, and particularly on the whole distribution region.

The objective of the present study was the comprehensive evaluation of $S$. pylzovi population genetic diversity, genetic structure, and population demographic history by analyzing mtDNA sequence data (the control region and $c y t b$ ), with an aim of understanding the influence of human activities on the population dynamics and water system change history in the upper reaches of the Yellow River. The study is expected to offer insights that would be useful for framing the conservation policies and for preservation of S. pylzovi.

\section{MATERIAL AND METHODS}

\section{Sampling and DNA sequence}

Specimens were collected with gill nets during the spring of 2013 from Yellow River at an altitude of 1500-3500 m, covering the entire region known for the distribution of $S$. pylzovi (Figure 1). All the specimens were immediately preserved in anhydrous ethanol for laboratory analyses. A total of 304 individuals were obtained from nine locations, including the Linxia (XH) range of the Xiahe River, Luqu (THS) and Hezheng (YT) ranges of the Taohe River, Minhe (HS) range of the Huangshui River, Weiyuan (WY) range of the Weihe River, and Yuzhong (YZ), Yingjing (YJ), Maqu (MQ), and Mentang (MT) ranges of the Yellow River. For our $S$, pylzovi analysis, we considered these nine groups to be distinct populations based on the distribution range.

Genetics and Molecular Research 15 (3): gmr.15038480 


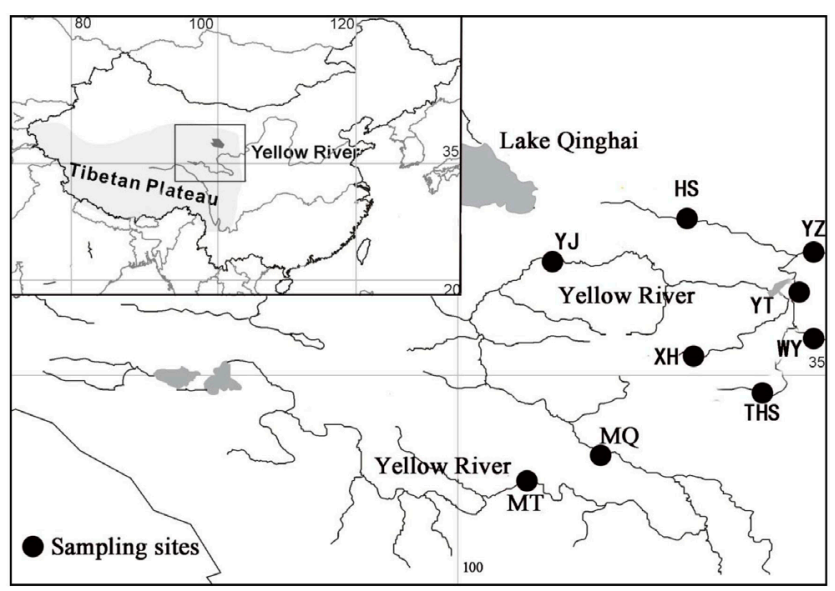

Figure 1. Map of the upper reaches of the Yellow River showing the sampling sites for Schizopygopsis pylzovi.

Total genomic DNA was extracted from the muscle tissue using phenol/chloroform extraction (Sambrook and Russell, 2001). A segment of $694 \mathrm{bp}$ from the mitochondrial control region was amplified using the primers (GEDL200: 5'-CAC CCC TGG CTC CCA AAG CCA G-3'; GEDH860: 5'-AGG GGT TTG ACA AGA ATA ACA GGA-3') reported by Zhao et al. (2011). The mitochondrial cyt $b$ (1140 bp) was amplified using the universal primers L14724 (5'GAC TTG AAA AAC CAC CGT TG-3') and H15915 (5'-CTC CGA TCT CCG GAT TAC AAG AC-3'). The polymerase chain reactions (PCRs) were performed in a $30-\mu \mathrm{L}$ volume that included $21.25 \mu \mathrm{L}$ molecular grade water, $3.0 \mu \mathrm{L} 10 \mathrm{X}$ PCR buffer, $1.5 \mu \mathrm{L}$ each primer $(10 \mathrm{mM}), 1.5 \mu \mathrm{L}$ dNTPs $(10 \mathrm{mM}), 0.375 \mu \mathrm{L}$ Taq polymerase, and $1 \mu \mathrm{L}$ template DNA. The PCR conditions were as follows: initial denaturation at $94^{\circ} \mathrm{C}$ for 5 min followed by 30 cycles of denaturation at $94^{\circ} \mathrm{C}$ for $30 \mathrm{~s}$, annealing at $53^{\circ} \mathrm{C}$ for $30 \mathrm{~s}$, extension at $72^{\circ} \mathrm{C}$ for $1 \mathrm{~min}$, and a final extension at $72^{\circ} \mathrm{C}$ for $10 \mathrm{~min}$, followed by a hold at $4^{\circ} \mathrm{C}$. The PCR products were analyzed on $1 \%$ agarose gels by ethidium bromide staining and purified using TaKaRa DNA Purification Kit from TaKaRa Bio Inc. (Shanghai, China). The purified DNA was sent to Shanghai Invitrogen Biotechnology Co., Ltd. (Shanghai, China) for bidirectional sequencing with the PCR primers.

\section{Data analysis}

The peaks obtained in the sequencing were checked by the Chromas 1.45 software; forward and reverse sequences were assembled and edited with the SeqMan program (DNASTAR Inc., WI, USA). The DNA sequence from each specimen, generated in the present study, was compared and aligned using ClustalX 1.8 (Thompson et al., 1997). The phylogenetic congruence of the mtDNA control region and $c y t b$ datasets was examined by PAUP V4 (Swofford, 2002). For sequence comparisons, pairwise genetic distance estimation and neighbor joining $(\mathrm{NJ})$ tree construction was done, based on the Kimura 2-parameter (K2P) distance model, using the MEGA version 5.0 software (Tamura et al., 2011). The number of haplotypes, nucleotide diversity $(\pi)$, haplotype diversity $(h)$, and mismatch analysis were estimated with DnaSP 4.0 (Rozas et al., 2003). Analysis of molecular variance (AMOVA) was used to assess the population structure and geographical pattern for distribution of the main genetic variation using Arlequin 3.0 (Excoffier et al., 2000). The pairwise genetic

Genetics and Molecular Research 15 (3): gmr.15038480 
differentiation $\left(F_{\mathrm{ST}}\right)$ values were estimated to assess the genetic divergence among all the populations (Schneider et al., 2000). The statistical significance of the total and pairwise genetic differentiation was estimated by comparing the observed distribution with a null distribution generated by 10,000 replicates. Population expansion history was inferred by neutrality test statistics of the Tajima's D (1989) and Fu's Fs tests (1997) (Rogers and Harpending, 1992).

\section{RESULTS}

\section{Sequence polymorphism}

The 694-bp sequences obtained from 304 S. pylzovi individuals were aligned with the mtDNA control region. These sequences had 63 variable sites including 21 singleton and 42 parsimony informative sites, and no indels. The average nucleotide base composition was $30.9 \%$ adenine $(A), 30.8 \%$ thymine $(\mathrm{T}), 23.3 \%$ guanine $(\mathrm{G})$, and $15.0 \%$ cytosine $(\mathrm{C})$, which was consistent with the mitochondrial nucleotide composition characteristic of the control region in other vertebrates. The $\mathrm{A}+\mathrm{T}$ content $(61.7 \%)$ was obviously higher than the $\mathrm{G}+\mathrm{C}$ content (38.3\%; Fu, 1997).

The amplified cyt $b$ fragment was $1140 \mathrm{bp}$. The sequence contained 201 variable sites, including 89 parsimony informative sites and 112 single mutation sites. The nucleotide composition comprised of $25.4 \% \mathrm{~A}, 30.9 \% \mathrm{~T}, 26.7 \% \mathrm{G}$, and $17.0 \% \mathrm{C}$. The composition reveals that the $c y t b$ is an $\mathrm{A}+\mathrm{T}-$ rich region of the mitochondrial genome.

\section{Population genetic diversity}

The partition-homogeneity test of 304 individuals revealed no significant incongruence between the control region and $c y t b(\mathrm{P}=0.27)$. The apparent congruence justified the combination of the two partial sequences in phylogenetic analysis of $1835 \mathrm{bp}$ of the mitochondrial genome. The genetic diversity of S. pylzovi was analyzed based on the combined data (Table 1). One hundred and twelve haplotypes were found in 304 individuals, high haplotype diversity $(h=$ $0.985 \pm 0.002)$ and low nucleotide diversity $(\pi=0.0055 \pm 0.0008)$ were observed, but there were obvious differences among the populations from the different geographic regions. The haplotype diversity was highest in the Minhe (HS) range of Huangshui River and lowest in the Weiyuan (WY) range of Weihe River. The nucleotide diversity was highest in the Yongjing (YZ) range of Yellow River and lowest in the Weiyuan (WY) range of Weihe River.

Table 1. Population codes, sample size, and parameters of genetic diversity in nine Schizopygopsis pylzovi
populations.
\begin{tabular}{l|l|c|c|c|c}
\hline Code & Location & Sampling size & $\begin{array}{c}\text { Numbers of } \\
\text { haplotypes }\end{array}$ & $\begin{array}{c}\text { Haplotype } \\
\text { diversity (h) }\end{array}$ & $\begin{array}{c}\text { Nucleotide } \\
\text { diversity }(\pi)\end{array}$ \\
\hline MQ & Yellow River, Maqu & 43 & 21 & 0.951 & 0.0035 \\
\hline MT & Yellow River, Mentang & 27 & 8 & 0.897 & 0.0033 \\
\hline YJ & Yellow River, Yongjing & 25 & 6 & 0.833 & 0.0041 \\
\hline YZ & Yellow River, Yuzhong & 35 & 17 & 0.934 & 0.0052 \\
\hline THS & Taohe River, Luqu & 51 & 13 & 0.959 & 0.0041 \\
\hline YT & Taohe River, Hezheng & 17 & 8 & 0.926 & 0.0042 \\
\hline XH & Xiahe River, Linxia & 36 & 13 & 0.982 & 0.0037 \\
\hline HS & Huangshui River, Minhe & 48 & 22 & 0.623 & 0.0052 \\
\hline WY & Weihe River, Weiyuan & 304 & 112 & 0.985 & 0.0007 \\
\hline Total & & & & 0.0055 \\
\hline
\end{tabular}

Genetics and Molecular Research 15 (3): gmr.15038480 


\section{Population structure}

AMOVA among the populations of $S$. pylzovi revealed that most of the molecular variance (69.64\%) occurred among individuals within the populations; the rest of the variation $(30.36 \%)$ was due to the differences among the populations (Table 2). Significant genetic differentiation was observed among the nine populations $\left(F_{\mathrm{ST}}=0.30364, \mathrm{P}=0.00\right)$. Pairwise $F_{\text {ST }}$ values revealed significant divergences between the populations $(\mathrm{P}<0.01) ; F_{\mathrm{ST}}$ value between MT and WY was highest (0.6156) and that between YZ and YJ was lowest (0.0706; Table 3).

Table 2. Analysis of molecular variance (AMOVA) among the Schizopygopsis pylzovi populations.

\begin{tabular}{|c|c|c|c|c|c|c|}
\hline Source of variation & d.f. & Sum of squares & $\begin{array}{c}\text { Variance } \\
\text { components }\end{array}$ & $\begin{array}{c}\text { Percentage of } \\
\text { variation }\end{array}$ & $\begin{array}{c}\text { Fixation } \\
\text { index }\end{array}$ & Significance \\
\hline Among populations & 8 & 281.218 & $0.98728 \mathrm{Va}$ & 30.36 & 0.30364 & $\mathrm{P}=0.00$ \\
\hline Within populations & 295 & 667.943 & $2.26422 \mathrm{Vb}$ & 69.64 & & \\
\hline Total & 303 & 949.161 & 3.25150 & & & \\
\hline
\end{tabular}

Table 3. Pairwise $F_{\mathrm{ST}}$ values (below the diagonal line) and associated $\mathrm{P}$ values (above the diagonal line) among the Schizopygopsis pylzovi populations.

\begin{tabular}{l|c|c|c|c|c|c|c|c|c}
\hline Group & MQ & THS & XH & HS & YZ & YT & WY & MT & YJ \\
\hline MQ & - & 0.0000 & 0.0000 & 0.0000 & 0.0000 & 0.0000 & 0.0000 & 0.0000 & 0.0000 \\
\hline THS & 0.4231 & - & 0.0000 & 0.0000 & 0.0000 & 0.0000 & 0.0000 & 0.0000 & 0.0000 \\
\hline XH & 0.3149 & 0.2331 & - & 0.0000 & 0.0000 & 0.0000 & 0.0000 & 0.0000 & 0.0000 \\
\hline HS & 0.2674 & 0.3224 & 0.2085 & - & 0.0000 & 0.0000 & 0.0000 & 0.0000 & 0.0000 \\
\hline YZ & 0.2024 & 0.2955 & 0.1138 & 0.1083 & - & 0.0000 & 0.0000 & 0.0000 & 0.0090 \\
\hline YT & 0.4488 & 0.3689 & 0.3618 & 0.2052 & 0.2523 & - & 0.0000 & 0.0000 & 0.0000 \\
\hline WY & 0.6022 & 0.4367 & 0.5183 & 0.4345 & 0.4439 & 0.3723 & - & 0.0000 & 0.0000 \\
\hline MT & 0.1064 & 0.3544 & 0.2424 & 0.2084 & 0.1386 & 0.4274 & 0.6156 & - & 0.0000 \\
\hline YJ & 0.1789 & 0.3823 & 0.1939 & 0.1433 & 0.0706 & 0.3105 & 0.5923 & 0.1608 & - \\
\hline
\end{tabular}

\section{Phylogenetic analyses}

With the close genetic relationship between Gymnocypris eckloni and Platypharodon extremus as an outgroup, the NJ phylogenetic tree was constructed using the combined data (Figure 2). It showed that each geographic population did not form its own single group, but the different populations were overlapping each other. On comprehensive analysis, we observed no significant genetic differentiation among the geographic populations.

\section{Historical demography}

The population expansion of $S$. pylzovi was estimated by mismatch distribution of the haplotypes using the neutrality test statistics of the Tajima's D and Fu's Fs tests. The mismatch distribution was unimodal and departed from the expected equilibrium distribution (Figure 3). Tajima's D $(-1.922, \mathrm{P}<0.05)$ and Fu's Fs $(-122.767, \mathrm{P}<0.01)$ were negative and statistically significant. With the ecological environment and water system of the Tibetan plateau experiencing violent change during the uplift of the Tibetan plateau, a recent population expansion of S. pylzovi seems to have occurred. 


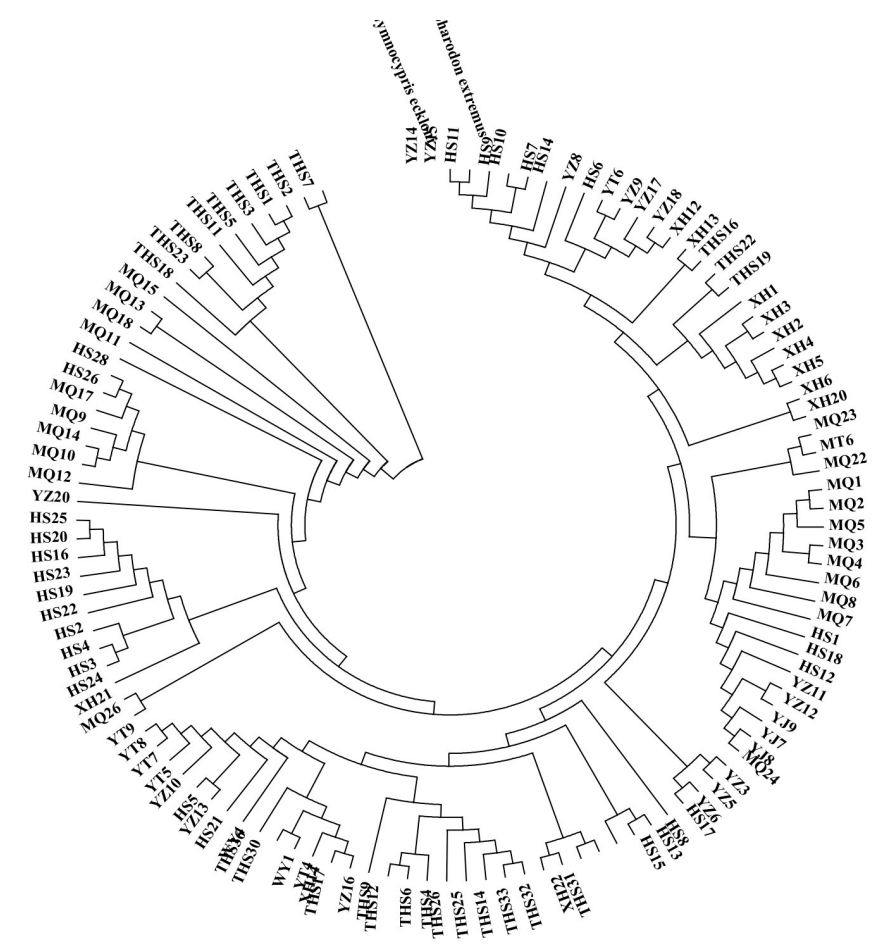

Figure 2. Phylogenetic tree of Schizopygopsis pylzovi constructed using the neighbor-joining method inferred from the combination of the control region and cytochrome $b$ sequences $(1835 \mathrm{bp}$ ) among nine populations. Names of the haplotypes follow population codes showing the population from which they were found and were numbered sequentially.

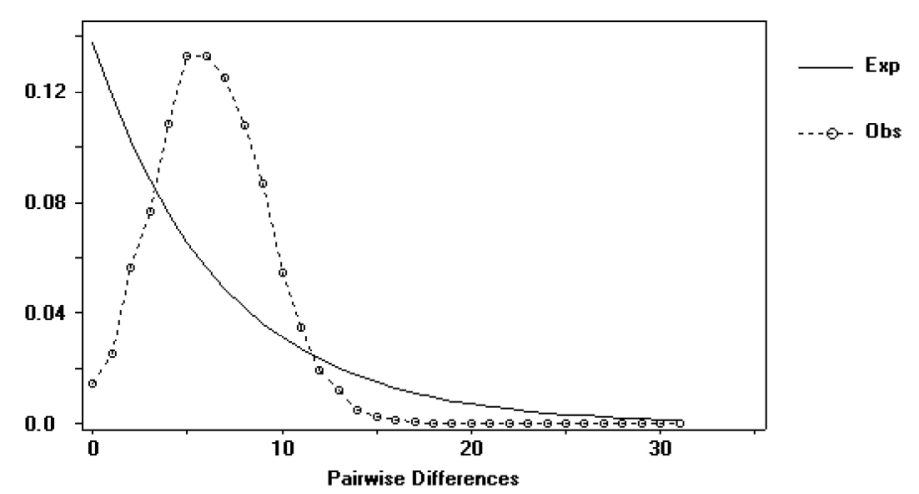

Figure 3. Mismatch distribution of the haplotypes after combining the control region and cytochrome $b$ sequences (1835 bp) of Schizopygopsis pylzovi.

\section{DISCUSSION}

Genetic diversity, which is the basis for biological diversity, is the assurance of evolutionary potential and is also directly related to species conservation and regeneration. 
The haplotype diversity $(h)$ of $S$. pylzovi inferred from 304 individuals was higher $(h=0.985$ \pm 0.002 ) than that of S. prenanti (Song et al., 2008), Gymnodipty chuspachycheilus (Su et al., 2012), and Gymnocypris przewalskii (Chen et al., 2006). It was also higher than that of S. pylzovi, which live in other regions (Qi et al., 2007). However, the nucleotide diversity ( $\pi$ $=0.0055 \pm 0.0008)$ of $S$. pylzovi was lower than those of the abovementioned species, the reason being that the fish living in Tibetan plateau was impacted by bottleneck effect during Quaternary glaciation. This is consistent with the opinions of Qi et al. (2007) and Zhao et al. (2006). The genetic diversity of WY population was the lowest among the nine populations in terms of the haplotype diversity, nucleotide diversity, and genetic distance view. The cause for these observations could be that Weihe River falls into the Yellow River in Xian, which is located in the middle reaches of the Yellow River and is not conducive to the survival of Schizothoracinae fishes. Some geographers think that Weihe river is an ancient river from the Yellow River that separated before the Cenozoic era (Clapp, 1922; Lin et al., 2001) and that the Yellow River trail was swerved from Liujiaxia due to the upliftment from Yuzhong to Niaoshu mountain in west Qinling mountains. Therefore, we speculated that S. pylzovi was continuously distributed in the upstream of the Yellow River before the Cenozoic era; however, populations of fishes were separated in Weihe River after the geological uplift. Gene interchange between the WY and other populations of S. pylzovi was cut off, so the WY population genetic diversity was reduced by the founder effect. These results are consistent with those obtained for Gymnodiptychus pachycheilus weiheensis (Zhang et al., 2013); these authors believe that the WY populations may have suffered serious bottlenecks in the history. Group analysis of the bases in $S$. pylzovi mitochondrial gene reflects this historical fact.

AMOVA showed that most of the genetic divergence (69.64\%) occurred among the individuals within the populations. This high genetic variation might have been caused by population diffusion (Serena et al., 2005) because of the climate of the Tibetan plateau. Since the Quaternary period, changes in the formation of species, diffusion, and genetic structure have been very important (Avise et al., 1998; Hewitt, 1999). Significant genetic differentiation among the populations $\left(F_{\mathrm{ST}}=0.30364, \mathrm{P}=0.00\right)$ was observed. Statistical tests revealed that $F_{\mathrm{ST}}$ values between two populations were significant and a certain degree of differentiation was noted among the populations, which might be related to the poor spreading ability and related gene communication channel of $S$. pylzovi being blocked (Avise et al., 1987). Based on the sampling figure (Figure 1) and the pairwise $F_{\mathrm{ST}}$ values (Table 3), it is obvious that the pairwise $F_{\mathrm{ST}}$ value provides a positive correlation with geographic distance. The $F_{\mathrm{ST}}$ value between $\mathrm{YJ}$ and $\mathrm{YZ}$ was lowest because of complete gene exchange for the shortest distance in the mainstream of the Yellow River and the absence of any barrier. Individuals from same local population were not monophyletic as revealed by the phylogenetic tree (Figure 2), suggesting that $S$. pylzovi from a common ancestor group had gene exchanges between the groups. The time of geographical isolation between the existing drainage patterns of the formation was not long enough for the populations to reach significant genetic isolation or for differentiation of monophyletic levels.

Neutral inspection is sensitive to the time of geographic expansion; large negative value $(\mathrm{Fs}=-122.767)$ hints at recent population expansion events in S. pylzovi (Su et al., 2001). Mismatch-distribution of the haplotypes was a clear unimodal map (Figure 3); it also showed that a population expansion event had happened. The results of system geographical patterns of the pedigree and population genetic structure can provide a scientific basis for species conservation strategies and fishery management measures. Due to the unique geography of the upstream regions of Yellow River and geological and ancient climate changes experienced

Genetics and Molecular Research 15 (3): gmr.15038480 
in the Tibetan plateau, many fishes showed strong adaptability to plateau hypoxia, low temperature, strong radiation, and other special environmental conditions during the long-term evolution. In recent years, with changes in the natural geographical climate, water pollution, soil erosion, and wading engineering constructions, many of spawning grounds, feeding grounds, wintering grounds, and migration routes of $S$. pylzovi have been seriously affected. Furthermore, a large number of adult fish are poached because of the over-consumption of wild products in the market. Six national conservation areas for aquatic germplasm resources were built to reduce the negative influence of hydropower project and for the protection of rare and peculiar fish populations and maintenance of fish diversity in the upstream regions of the Yellow River. These conservation areas aim at sustainable use of fish resources. The present article comprehensively evaluated the existing distribution of $S$. pylzovi for genetic diversity and genetic structure at the population level and found that the genetic diversity was higher except for the WY population. Because of the low genetic variation in the WY population of S. pylzovi, the authors suggest that in situ conservation measures must be taken.

\section{Conflicts of interest}

The authors declare no conflict of interest.

\section{ACKNOWLEDGMENTS}

Research supported by the National Natural Science Foundation of China (\#31460560) and the Principal Fund of Gansu Normal University for Nationalities (\#2014-05).

\section{REFERENCES}

Avise JC (2000). Phylogeography: The History and Formation of Species. Harvard University Press, London, 9-32.

Avise JC, Arnold J, Ball RM, Bermingham E, et al. (1987). Intraspecific phylogeography: the mitochondrial DNA bridge between population genetics and systematics. Ann. Rev. Ecol. Syst. 18: 489-522. http://dx.doi.org/10.1146/annurev. es.18.110187.002421

Avise JC, Walker D and Johns JC (1998). Speciation durations and Pleistocene effects on vertebrate phylogeography. Proc. Biol. Sci. 265: 1707-1712.http://dx.doi.org/10.1098/rspb.1998.0492

Billingtong N and Hebert PDN (1991). Mitochondrial DNA diversity in fishes and its implications for introductions. Can. J. Fish. Aquat. Sci. 48: 80-94. http://dx.doi.org/10.1139/f91-306

Chen DQ, Zhang CL, Cheng LU and Zhang X (2006). Polymorphism of D-loop sequence from mitochondrial genomes of different brood stocks of Gymnocypris przewalskii (Kessler). J. Fish. Sci. China 13: 800-806 (In Chinese with English abstract).

Cheng F, Li W, Klopfer M, Murphy BR, et al. (2015). Population genetic structure and its implication for conservation of Coreius guichenoti in the upper Yangtze River. Environ. Biol. Fish 98: 1999-2007. http://dx.doi.org/10.1007/ s10641-015-0419-z

Clapp FG (1922). The HuangHo, Yellow River. Geogr. Rev. 12: 1-18. http://dx.doi.org/10.2307/208653

Craft KJ, Pauls SU, Darrow K, Miller SE, et al. (2010). Population genetics of ecological communities with DNA barcodes: an example from New Guinea Lepidoptera. Proc. Natl. Acad. Sci. USA 107: 5041-5046. http://dx.doi. org/10.1073/pnas.0913084107

Duan ZY, Zhao K, Peng ZG, Li JB, et al. (2009). Comparative phylogeography of the Yellow River schizothoracine fishes (Cyprinidae): variance, expansion, and recent coalescence in response to the Quaternary environmental upheaval in the Tibetan Plateau. Mol. Phylogenet. Evol. 53: 1025-1031.http://dx.doi.org/10.1016/j.ympev.2009.03.034

Excoffier L, Smouse PE and Quattro JM (2000). Analysis if molecular variance inferred from metric distances among DNA haplotypes: application to human mitochondrial DNA restriction data. Genetics 131: 343-359.

Fu YX (1997). Statistical tests of neutrality of mutations against population growth, hitchhiking and background selection. Genetics 147: 915-925.

Genetics and Molecular Research 15 (3): gmr.15038480 
He DK and Chen YF (2007). Molecular phylogeny and biogeography of the highly specialized level schizothoracine fishes (Teleostei: Cyprinidae) inferred from cytochrome b sequences. Chin. Sci. Bull. 52: 777-788 (In Chinese). http:// dx.doi.org/10.1007/s11434-007-0123-2

Hewitt GM (1999). Post-glacial re-colonization of European biota. Biol. J. Linnean Soc. 68: 87-112. http://dx.doi. org/10.1111/j.1095-8312.1999.tb01160.x

Lin AM, Yang ZY, Sun ZM and Yang TS (2001). How and when did the yellow river develop its square bend? Geology 29: 951-954 (In Chinese). http://dx.doi.org/10.1130/0091-7613(2001)029<0951:HAWDTY>2.0.CO;2

Liu HL, Zhang RQ, Geng ML, Zhu JY, et al. (2016). Chloroplast analysis of Zelkova schneideriana (Ulmaceae): genetic diversity, population structure, and conservation implications. Genet. Mol. Res. 15: doi: http://dx.doi.org/10.4238/ gmr.15017739.

Paul OA, Hyuk JL, Kathryn RE, Romulus A, et al. (2011). Genetic structure and gene flow in an endangered native tilapia fish (Oreochromis esculentus) compared to invasive Nile tilapia (Oreochromis niloticus) in Yala swamp, East Africa. Conserv. Genet. 12: 243-255. http://dx.doi.org/10.1007/s10592-010-0136-2

Qi DL, Guo SC, Zhao XQ, Yang J, et al. (2007). Genetic diversity and historical population structure of Schizopygopsis pylzovi (Teleostei: Cyprinidae) in the Qinghai-Tibetan Plateau. Freshwater Biol. 52: 1090-1104. http://dx.doi. org/10.1111/j.1365-2427.2007.01731.x

Rogers AR and Harpending H (1992). Population growth makes waves in the distribution of pairwise genetic differences. Mol. Biol. Evol. 9: 552-569.

Rozas J, Sanchez-DelBarrio JC, Messequer X and Rozas R (2003). DnaSP, DNA polymorphism analyses by the coalescent and other methods. Bioinformatics 18: 2496-2497. http://dx.doi.org/10.1093/bioinformatics/btg359

Sambrook J and Russell DW (2001). Molecular Cloning: A Laboratory Manual $3^{\text {rd }}$ ed. Cold Spring Harbor Laboratory Press, New York.

Schneider S, Roessli D and Excoffier L (2000). ArlequinVer 2.000: A software program for population genetics data analysis. Genetics and Biometry Laboratory, University of Geneva, Switzerland.

Serena Z, Fabrizio S and Giuseppe C (2005). Diversity of mitochondrial DNA of the endangered white-clawed crayfish (Austropotamobius italicus) in the Po River catchment. Freshwater Biol. 50: 1262-1272. http://dx.doi.org/10.1111/ j.1365-2427.2005.01385.x

Simplicio RR, Waldschmidt AM, Amorim MB, Almeida BS, et al. (2015). Genetic diversity and structure in natural populations of Maytenus truncata Reiss, 1861, a medicinal plant vulnerable to extractivism in Bahia State, Brazil. Genet. Mol. Res. 14: 18241-18248. http://dx.doi.org/10.4238/2015.December.23.11

Song ZB, Song J and Yue BS (2008). Population genetic diversity of Prenant's schizothoracin, Schizothorax prenanti, inferred from the mitochondrial DNA control region. Environ. Biol. Fish. 3: 247-252. http://dx.doi.org/10.1007/ $\underline{\text { s10641-007-9197-6 }}$

Su B, Fu YX, Wang YX, Jin L, et al. (2001). Genetic diversity and population history of the red panda (Ailurus fulgens) as inferred from mitochondrial DNA sequence variations. Mol. Biol. Evol. 18: 1070-1076.http://dx.doi.org/10.1093/ oxfordjournals.molbev.a003878

Su JH, Zhang YP, Lou ZY, Liu HZ, et al. (2012). Genetic structure of Gymnodiptychus pachycheilus from the upper reaches of the Yellow River as inferred from mtDNA control region. Acta Ecol. Sin. 32: 4191-4198. (In Chinese with English abstract). http://dx.doi.org/10.5846/stxb201106070757

Swofford DL (2002). PAUP*: Phylogenetic analysis using parsimony (*and other methods). Version 4. Sinauer Associates, Sunderland, Massachusetts.

Tamura K, Peterson D, Peterson N, Stecher G, et al. (2011). MEGA5: Molecular Evolutionary Genetics Analysis Using Maximum Likelihood, Evolutionary Distance, and Maximum Parsimony Methods. Mol. Biol. Evol. 10: 2731-2739. http://dx.doi.org/10.1093/molbev/msr121

Thompson JD, Gibson TJ, Plewniak F, Jeanmougin F, et al. (1997). The CLUSTAL-X windows interface: flexible strategies for multiple sequence alignment aided by quality analysis tools. Nucleic Acids Res. 25: 4876-4882. http:// dx.doi.org/10.1093/nar/25.24.4876

Wu GCC, Chiang HC, Chou YW, Wong ZR, et al. (2010). Phylogeography of yellowfin tuna (Thunnus albacares) in the western Pacific and the western Indian Oceans inferred from mitochondrial DNA. Fish. Res. 3: 248-253. http:// dx.doi.org/10.1016/j.fishres.2010.03.015

Wu XW (1964). The cyprinid fishes of china. Shanghai Science and Technology Press, Shanghai (In Chinese).

Wu YF (1984). The study of fish System classification of schizothorax in china. Plateau biological of biology 3:119-140 (In Chinese).

Wu YF and Wu CZ (1992). Qinghai-Tibet Plateau Fishes. Sichuan Science and Technology Press, Chengdou (In Chinese).

Zhang FT, Duan YJ, Cao SM, Wang JW, et al. (2012). High genetic diversity in population of Lepturichthys fimbriata from the Yangtze River revealed by microsatellite DNA analysis. Chin. Sci. Bull. 57: 487-491. http://dx.doi.org/10.1007/ $\underline{\text { s11434-011-4704-8 }}$

Genetics and Molecular Research 15 (3): gmr.15038480 
Zhang YP, Du YY, Hu YB, Lou ZY, et al. (2013). Discussion on taxonomic status of Gymnodiptychus pachycheilus weiheensis Wang et Song. Acta Zootaxonomica Sinica, 38: 705-713 (In Chinese with English abstract).

Zhao K, Yang GS, Li JB and He SP (2006). Phylogenetic strucuture of Schizopygopsis pylzovi populations from mitochondrial cytochrome b gene sequence variations. Acta Hydrobiol. Sin. 30: 129-133 (In Chinese with English abstract).

Zhao K, Duan ZY, Peng ZG, Gan XN, et al. (2011). Phylogeography of the endemic Gymnocypris chilianensis (Cyprinidae): sequential westward colonization followed by allopatric evolution in response to cyclical Pleistocene glaciations on the Tibetan Plateau. Mol. Phylogenet. Evol. 59: 303-310.http://dx.doi.org/10.1016/j.ympev.2011.02.001

Genetics and Molecular Research 15 (3): gmr.15038480 